Published by Faculty of Islamic Civilization Studies, KUIS

\title{
FAHAMAN PELAMPAU RAJAH SOLAIMAN MOVEMENT (RSM) SEBAGAI SEBUAH GERAKAN ISLAM DI FILIPINA
}

Marlon Pontino Guleng@ Muhammad Yusuf Marlon Abdullah ${ }^{1}$, Razaleigh Muhamat @ Kawangit ${ }^{2}$, Zulkefli Hj Aini ${ }^{2}$

${ }^{1}$ Jabatan Dakwah dan Usuluddin, Fakulti Pengajian Peradaban Islam, KUIS.

2 Jabatan Dakwah \& Kepimpinan, Fakulti Pengajian Islam, UKM.

Correspondence Author: Marlon Pontino Guleng@ Muhammad Yusuf Marlon Bin Abdullah, Jabatan Dakwah \& Pengurusan, Akademi Islam, KUIS, 43000 Bangi, Selangor. Tel: 019-3043907. Emel: yusufmarlon@kuis.edu.my

\begin{abstract}
ABSTRAK
Gerakan aktiviti Islam di Filipina sering menghadapi cabaran disebabkan fahaman yang melampau daripada sebahagian pemimpin Muslim yang sering dikaitkan dengan pembunuhan, penculikan, terorisme dan sebagainya. Kertas ini bertujuan untuk membincangkan perbuatan ekstremis atau radikal gerakan Islam di Filipina. Kajian literatur ini memberi penekanan terhadap fahaman pelampau dalam Rajah Solaiman Movement yang membawa kepada salah tanggap bukan Muslim terhadap Islam sebagai agama teroris. Kajian ini juga merangkumi pandangan ulama terhadap ekstrimisme atau radikalisme gerakan Islam di seluruh dunia.
\end{abstract}

Kata Kunci: Gerakan Islam, Rajah Solaiman Movement (RSM), Abu Sayyaf Group (ASG), Moro Islamic Liberation Front (MILF)

\section{(EXTREMISM OF RAJAH SOLAIMAN MOVEMENT (RSM) AS AN ISLAMIC MOVEMENT IN THE PHILIPPINES)}

\begin{abstract}
The movement of Islamic activities in the Philippines has always dealt with various obstacles due to the misleading ideologies of some Muslim leaders, which commonly engage with murdering, kidnapping, terrorism, and so on. In that case, this paper aims to discuss extremism or the radicalism of Islamic movements in the Philippines. The research literature will discuss the extreme ideology of the Rajah Solaiman Movement (RSM), which gives a negative understanding among non-Muslims towards Islam as a terrorist religion. The research will include some discussion of Muslim scholars about the extremism or radicalism ideas in the Islamic movements worldwide.
\end{abstract}

Keywords: Islamic Movement, Rajah Solaiman Movement (RSM), Abu Sayyaf Group (ASG), Moro Islamic Liberation Front (MILF) 


\section{Pengenalan}

Gerakan Islam ialah mendukung cita-cita Islam seperti pembentukan peribadi, menegakkan pemerintahan, menyatukan barisan dan mengembalikan kedudukan pemerintah Khalifah dengan mempunyai rancangan dan rangka kerja yang tersusun dan lengkap (Abdul Wahab Zakaria, 1994). Manakala menurut R. Hrair Dekmejian (1995), gerakan Islam merupakan sebahagian daripada istilah-istilah seperti $a l-B a$ 'th al-Islam (Islamic resurrection), al-Sahwah al-Islamiyyah (Islamic Awakening), Ihya' al-Din (religious revival), al-Usuliyyah al-Islamiyyah (Islamic Fundamentalism), alTayyar al-Islami (Islamic Current), al-Ittijah al-Islamiyyah (Islamic Tendency). Penggerak dalam gerakan Islamisasi dipanggil sebagai Islamist, fundamentalist dan revivalist.

Gerakan Islamisasi pada dasarnya timbul akibat daripada tiga perkara asas, antaranya ialah kesedaran beragama dalam kalangan penganut Islam, komited mengembalikan kegemilangan Islam pada zaman Rasulullah SAW dari aspek sosial, politik, budaya yang berlandaskan ajaran Islam sebenar dan perkara ketiga ialah mengembalikan kekuatan umat Islam yang makin lama makin hilang akibat daripada berpecahan ideologi, pemikiran dan pemahaman terhadap agama Islam itu sendiri (Cesar Adib Majul, 1985). Ketiga-tiga perkara asas yang dinyatakan di atas merupakan tujuan utama dalam sesuatu gerakan untuk menjaga dan memilihara agama Islam daripada sebarang kerosakan.

Gerakan Islamisasi di Filipina merupakan kesinambungan daripada tugas yang telah dimulakan sejak abad ke-9 sehingga abad ke-16 sebelum kedatangan penjajah Sepanyol yang diketuai oleh Ferdinand Magellan pada abad ke-16 Masihi. Islamisasi diteruskan dengan kedatangan Raja Makhdum seorang pendakwah daripada Indonesia pada awal abad ke-14. Begitu juga pada akhir abad ke-14 tugas Islamisasi diteruskan oleh Raja Baguinda. Hasil daripada pertembungan antara penganut Islam dan Kristian maka tercetuslah beberapa siri peperangan yang dinamakan 'Moro Wars' . Gerakan Islamisasi terus menerus sehingga terbentuknya beberapa gerakan hasil daripada kesedaran beragama dalam kalangan masyarakat Muslim itu sendiri. Misalnya, pada 1 Mei 1968, Muslim Independence Movement (MIM) diasaskan oleh Datu Udtog bertujuan memerdekakan Mindanao dan mempertahankan umat Islam daripada pertubuhan yang dinamakan Ilongo Armed Group Association (ILAGA) yang terdiri daripada 200 ahli yang dilatih khas untuk membunuh dan menyembelih umat Islam (Cesar Adib Majul, 1985: 25-49).

Tidak cukup dengan itu, pada tahun 1971 terbentuklah sebuah pertubuhan yang dinamakan Moro National Liberation Front (MNLF) dan Bangsa Moro Liberation Front (BMLO) untuk menyelesaikan masalah antara umat Islam dan Kristian di selatan Filipina (Cesar Adib Majul, 1985: 52-56). Seterusnya, diikuti dengan penubuhan Ansar al-Islam pada tahun 70an yang diasaskan oleh Domocao Ahmad Alonto yang merupakan bekas Senator di Filipina. Begitu juga dengan penubuhan Muslim Association of the Philippines (MUSAPHIL) yang diasaskan pada 1964 iaitu ketika era pemerintahan Presiden Marcos (Cesar Adib Majul, 1985: 59-91). Tidak lupa juga kepada Moro Islamic Liberation Front (MILF) yang diasaskan oleh Hashim Salamat pada tahun 1984 dan selaku peneraju kerajaan di selatan Filipina kini (Yusuf Morales, t.th.).

Seterusnya pada tahun 2001, terbentuknya sebuah gerakan yang dinamakan sebagai Rajah Solaiman Movement (RSM) iaitu bertujuan untuk mengembalikan dan membina sebuah negara Islam di Filipina sempena nama seorang raja di Manila iaitu Rajah Solaiman. 


\section{Published by Faculty of Islamic Civilization Studies, KUIS}

Kebangkitan gerakan Islamisasi di Filipina berpunca daripada ketidakadilan layanan yang diamalkan oleh pihak berwajib terhadap umat Islam yang mengakibatkan penindasan dan penekanan terhadap kehidupan penduduk minoriti di negara tersebut, begitu juga dengan masalah yang dialami oleh Bangsamoro yang nampak tiada kesudahannya (Yusuf Morales, t.th.).

\section{Penubuhan Rajah Solaiman Movement (RSM)}

Penubuhan RSM berkait rapat dengan al-Harakah al-Islamiyyah (AHAI) atau lebih dikenali sebagai Abu Sayyaf Group (ASG) yang diasaskan oleh Abdul Rajak Janjalani. ASG diasaskan pada tahun 1989 bertujuan mengislamisasikan seluruh negara Filipina seperti yang direkodkan melalui video ucapan pengasasnya iaitu, 'Islam must govern not only in Sulu, but in the whole world. This is the objective of the Islamic movement. As for us, Allah permits, this will become a cause with our blood and soul we must be able to get Mindanao and let Islam govern. It is incumbent upon us to also include Visayas and Luzon to be governed by Islam. Even the entire Philippines, as mandated by Allah' (Carlos Agustin, 2005).

RSM merupakan suatu gerakan yang diasaskan pada tahun 2001 dan ahlinya terdiri daripada golongan yang dipanggil 'Balik Islam' atau golongan bukan Muslim yang memeluk Islam. Gerakan ini diasaskan oleh Ahmad Santos yang bermula atas nama Fi Sabilillah Da'wah and Media Foundation (FSDMFI) pada tahun 1995 setelah beliau sendiri memeluk Islam pada tahun 1993 di Islamic Studies Call and Guidance (ISCAG). Pada awal penubuhannya, seramai 20 orang mualaf yang menyertai latihan di Anda, Pangasinan, Pulau Luzon. RSM digunakan bagi memperingati raja Muslim pertama yang memerintah bandar Manila. Antara tujuan penubuhan gerakan ini ialah bercita-cita mengembalikan daulah Islamiah di Filipina kerana mereka percaya bahawa negara Filipina adalah negara Islam sebelum kedatangan Sepanyol (Rommel Banlaoi, 2006a). RSM memanggil ahlinya sebagai 'Balik Islam' dengan dua alasan. Pertama, beralasan bahawa semua manusia dilahirkan tanpa dosa namun disebabkan agama ibu bapanya yang sesat maka anak tersebut mewarisi kesesatan. Walau bagaimanapun, setelah memeluk Islam maka semua dosa-dosa tersebut telah terhapus. Kedua, RSM berpandangan bahawa negara Filipina sebelum kedatangan Sepanyol adalah negara Islam dan buktinya ialah Rajah Solaiman sebagai yang dipertuan di seluruh Manila (Asia Report No 110,2005 ).

Penulis berpandangan bahawa RSM merupakan sebuah gerakan yang tidak diasaskan menerusi perkauman (asabiyyah) seperti Moro National Liberation Front (MNLF) dan Moro Islamic Liberation Front (MILF) kerana kebanyakan ahlinya adalah terdiri daripada bukan dalam kalangan Moro yang bekerja di Tanah Arab dan tinggal di utara Filipina dan bukannya selatan. Seperkara lagi yang perlu diberikan perhatian ialah kawasan tempat kelahiran RSM bukan di Mindanao tetapi di kawasan penduduknya majoriti beragama Kristian dan pengasasnya juga adalah seorang mualaf.

\section{Matlamat Dan Tujuan Penubuhan}

Selain daripada matlamat asal yang dinyatakan di atas, terdapat beberapa maklamat yang ingin dicapai, antaranya ialah menyokong gerakan jihad di Mindanao ke arah menubuhkan sebuah negara Islam yang berpaksikan kepada undang-undang Islam, mengislamkan keseluruhan penduduk Filipina, memainkan peranan penting di Utara 
Filipina khususnya di Manila sebagai pusat pentadbiran (Mohammed Yakub Razzaque, 2006).

Kelahiran RSM melakukan suatu transformasi yang agak luar biasa kerana kebiasaannya gerakan Islamisasi di Filipina diasaskan oleh individu yang lahir dalam agama Islam khususnya Bangsamoro. Namun, dalam hal ini RSM dapat merubah kedudukan demografi yang didiami oleh umat Islam di luar kawasan Mindanao atas tujuan dan maksud yang sama iaitu mengislamkan seluruh penduduk Filipina.

\section{Pengasas Dan Fahaman}

Menurut Julkipli Wadi (2006), fahaman dan ideologi RSM digambarkan sebagai Jihad Islami yang membawa kepada jihad melawan musuh. RSM diasaskan oleh Hilarion del Rosario Santos III atau dikenali sebagai Ahmad Santos yang ditangkap di Bandar Zamboanga pada 26 October, 2005 (International Crisis Group, 2005). Ahmad Santos dilahirkan pada tahun 1971, beliau merupakan anak sulung daripada tiga adik beradik dan dibesarkan oleh datuk mereka yang merupakan seorang pesara tentera. Setelah gagal mendapatkan tempat daripada memasuki ketenteraan U.S. Navy beliau mencuba nasib dan bekerja di Arab Saudi selama enam bulan. Setelah kembalinya pada tahun 1992 (waktu itu belum memeluk Islam) beliau terpengaruh dengan sebuah saluran radio mingguan yang membincangkan tentang isu-isu Islam. Sejak daripada itu beliau berjinak-jinak dengan Islam dan sering menghadirkan diri di ISCAG. Pada tahun 1993 beliau menyatakan hasratnya untuk memeluk Islam dan diikuti oleh adiknya pada tahun 1994. Pada tahun 1995, Ahmad Santos mengasaskan sebuah pertubuhan yang dinamakan Fi Sabilillah Da'wa and Media Foundation (FSDMFI) dengan bantuan pegawai ISCAG iaitu Abdullah Gacuan. Matlamat utama penubuhan FSDMFI ialah "propagate the true essence of Islam and to correct misconceptions about Islam and Muslims", maksudnya menyebarkan kebenaran mesej Islam dan memperbetulkan tanggapan masyarakat terhadap agama Islam dan pengikutnya (Rodolfo Mendoza, 2005). Sejak daripada itu beliau sering keluar di radio, televisyen dan surat khabar untuk memberikan pengisian dan perkongsian tentang Islam sehingga mempunyai hubungan dengan Hashim Salamat selaku ketua MILF pada waktu itu. Seterusnya, Santos menjalinkan hubungan dengan ASG kerana berkahwin dengan Nurain Dongon, adik kepada Zainab iaitu isteri kepada ketua ASG.

Ahmad Santos merupakan beras kepada ketua ASG iaitu Khadaffy Janjalani yang sama-sama mendapat latihan dengan Sheikh Omar di Darul Imam Shafi'i, Marawi City dan juga di kem latihan MILF yang bertempat di Busrah, Butig Lanao del Sur (ICG, 2005).

Manakala penasihat gerakan ini ialah Reuben Lavilla atau lebih dikenali sebagai Sheikh Omar yang berperanan sebagai mufti kerana memiliki ilmu pengetahuan yang luas terhadap agama Islam serta mahir dalam ilmu al-Quran dan hadith. Lavilla adalah lulusan di Universiti Madinah dalam bidang Shariah dan undang-undang. Setelah tertangkapnya Ahmad Santos pada tahun 2005, beliau dilantik sebagai ketua RSM yang baru namun tidak bertahan lama kerana ditangkap pada bulan Julai tahun 2008 di Bahrain (Philippine Daily Inquirer, 2008).

Fahaman radikal dalam kalangan ahli RSM berpunca daripada ucapan jurucakap pertubuhan itu sendiri iaitu "you don't have to bring the war to Mindanao. We will bring it right to your doorstep" (SunStar, 2005). Maksudnya, anda tidak perlu datang membawa peperangan di Mindanao. Kami akan membawanya di hadapan pintu rumah kalian. Berdasarkan fahaman ini, sangat jelas bahawa tujuan utama RSM diwujudkan ialah untuk mencetuskan peperangan. Perkara ini terjadi kerana 
Published by Faculty of Islamic Civilization Studies, KUIS

ketidakadilan yang diamalkan oleh kerajaan Filipina yang sentiasa berat sebelah terhadap umat Islam sejak pemerintahan era Marcos lagi (1972-1986).

\section{Keahlian Dan Dana RSM}

Jumlah ahli RSM dianggarkan sebanyak 50 sehingga 100 orang. Walaupun jumlahnya kecil tetapi disebabkan bekerjasama dengan Abu Sayyaf Group (ASG), Jemaah Islamiah (JI) dan al-Qaedah ia mampu melaksanakan misinya (Rommel Banlaoi, 2006b). Namun jumlah keahlian tersebut berkurangan kepada 28 orang pada tahun 2006 setelah tertangkapnya pengasas gerakan tersebut (Hermogenes Esperon Jr. 2006). Difahamkan bahawa MILF menyediakan latihan khas kepada 50 orang ahli RSM pada bulan Disember tahun 2001 (Rodolfo Mendoza, 2005).

Dana RSM diterima daripada Abu Sayyaf Group (ASG), Jemaah Islamiah (JI) dan sebahagiannya melalui Overseas Filipino Worker's (OFW's) yang bekerja di Arab Saudi (Rommel Banlaoi, 2006b). Namun semua penajaan tersebut telah dihentikan setelah Fi Sabilillah Da'wah and Media Foundation (FSDMFI) ditutup kerana dikaitkan dengan terorisma.

\section{Strategi Operasi RSM}

Strategi RSM adalah menggabungkan dakwah dan jihad. Strategi utama gerakan RSM ialah mensasarkan ekonomi negara supaya dapat melemahkan sumber ekonomi negara yang menyokong terhadap memerangi umat Islam di Filipina termasuklah menanamkan ketakutan terhadap musuh. Kebanyakan operasi RSM disasarkan di bandar-bandar khususnya Manila (Rommel Banlaoi, 2006b). Kebanyakan operasinya menggunakan bom buatan sendiri untuk meletupkan beberapa kawasan yang telah disasarkan berbanding menggunakan senapang dan menyerang kawasan-kawasan tertentu.

Walaupun RSM mempunyai keahlian yang sedikit tetapi mempunyai kemampuan untuk melaksanakan rancangannya. Antara misi yang berjaya dilaksanakan ialah meletupkan sebuah kapal pada 27 Februari tahun 2004, sambutan Valentine's Day pada tahun 2005 dan beberapa siri serangan di Manila pada tahun 2005 (Alcuin Papa, 2007). Pengeboman ke atas sebuah kapal pada 27 Februari 2004 mengakibatkan kebakaran ke atas 10 ton kapal dan tenggelam di Pantai Manila begitu juga dengan anggaran kehilangan nyawa seramai 116 orang. Manakala pada 14 Februari 2005 pengeboman sebuah bas yang mengakibatkan kepada kematian seramai 4 orang dan mencederakan 64 orang. Walau bagaimanapun, difahamkan bahawa dalam kejadian ini seramai 3 orang ahli ASG mati ditempat kejadian (Tarra Quismundo \& Luige del Puerto, 2005).

Sebahagian laporan aktiviti RSM ialah percubaan bunuh ke atas bekas Presiden Macapagal Arroyo, meletupkan kedutaan Amerika Syarikat dan beberapa bangunan pusat perniagaan di Manila, penculikan dan pembunuhan beberapa pegawai kerajaan dan polis. Difahamkan bahawa antara rancangan RSM ialah penggunaan berani mati dalam kalangan ahlinya (Rodolfo Mendoza, 2005). Walau bagaimanapun, rancangan meletupkan diri dalam kalangan ahli belum dilaksanakan walaupun terdapat pengakuan daripada Ahmad Santos mengenai sebahagian ahlinya telah dilatih untuk itu dan bersedia untuk mati sebagai shahid. Ahmad Santos dan Sheikh Umar cuba mempengaruhi para ahlinya dengan menanam dalam fikiran mereka bahawa pengorbanan yang paling mulia ialah mengorbankan diri semata-mata kerana Allah dan Islam (Rommel Banlaoi, 2006b). 


\section{Perbahasan Ulama Terhadap Fahaman Pelampau Dalam Gerakan Islam}

Isu fahaman pelampau bagi sesetengah individu Muslim sudah lama wujud antaranya ialah kafir mengkafirkan sesama sendiri. Isu ini telah dibahaskan oleh Imam Hassan al-Banna dengan penjelasan yang panjang dalam Rukun Faham. Beliau menjelaskan bahawa hukum mengkafirkan saudara Muslim yang mengucapkan dua kalimah shahadah dan beramal dengan segala tuntutan shahadah iaitu mengesakan Allah SWT, menyembah Allah SWT, beriman dengan kitab-kitabNya, para Rasul, malaikat, hari akhirat, qada' dan qadar dan menunaikan segala kefarduan maka tidak seharusnya seseorang Muslim menghukumkannya sebagai kafir. Demikian juga tidak wajar sesiapapun mengkafirkannya sekiranya ia mengemukakan pandangan syaz (janggal) yang menyalahi pandangan kaum Muslimin atau melakukan beberapa perbuatan maksiat yang ditegah oleh Allah SWT. Ini kerana dengan pandangan syaz ini dan juga maksiat yang ia lakukan, dia masih seorang Muslim sekalipun ia dianggap sebagai ahli maksiat (Ali Abdul Halim Mahmud, 2003).

Manakala Dr. Yusuf al-Qaradhawi membahaskan isu pemikiran dan fahaman yang melampau dalam kitabnya al-Fatawa. Al-Qaradhawi menjelaskan bahawa masyarakat Islam seharusnya mengambil hukum kecuali dari sumber Islam yang sebenar dan bersih daripada penyelewengan dan penambahan yang mengakibatkan rosaknya umat Islam. Sumber yang sahih akan menghilangkan pemikiran yang ekstrim dan radikal. Bukanlah pandangan Islam tentang kehidupan sebagai pandangan pesimis yang mengatakan bahawa kehidupan itu kejam, jahat dan harus segera hancur. Mengambil kira bahawa manusia adalah makhluk Allah SWT yang memiliki kemuliaan dan harus dihormati mengikut haknya. Penerapan Islam pada zaman Rasulullah SAW telah membuktikan kebenaran pemikiran tersebut (Yusuf alQaradhawi, 2012).

\section{Kesimpulan}

Kajian ini dapat disimpulkan bahawa kehadiran kumpulan-kumpulan yang berpegang kepada fahaman pelampau dalam masyarakat majoritinya penduduk Kristian akan merugikan masyarakat Islam itu sendiri kerana sesuatu gerakan sepatutnya dijadikan satu wadah atau flatform dalam mengembalikan kegemilangan Islam di Filipina sebelum kedatangan penjajah Sepanyol pada abad ke-16.

\section{Rujukan}

Abdul Wahab Zakaria. (1994). Konsep Kepimpinan Dalam Islam. Petaling Jaya: ABIM.

Alcuin Papa. (2005). Police arrest suicide bomber. Philippine Daily Inquirer (Manila).

Ali Abdul Halim Mahmud. (2003). Syarah Usul 20 al-Imam Hasan al-Banna. Selangor: Dewan Pustaka Fajar.

Asia Report $\mathrm{N}^{\mathrm{o}} 110$. (2005). Philippines Terrorism: The Role of Militant Islamic Converts Crisis Group.

Carlos Agustin. (2005). State of radicalization in muslim communities in the Philippines. Paper presentation on the Regional conference on the radicalization of Moslem Communities in Southeast Asia Mandarin Oriental Hotel, Makati City, Philippines. 
Published by Faculty of Islamic Civilization Studies, KUIS

Cesar Adib Majul. (1985). The Contemporary Muslim Movement in the Philippines. United States of America: Mizan Press.

Hermogenes Esperon Jr. (2006). Perspective from the Military. Manila: Office of the Strategic and Special Studies, AFP.

International Crisis Group. (2005). Southern Philippines Background: Terrorism and the Peace Process. Singapore: t.pt.

Julkipli Wadi. (2006). Islamic nationalism and Philippine politics. Dlm. Teresa Encarnacion Tadem \& Noel Morada. Philippine Politics and Governance: Challenges to Democratization and Development. Quezon City: University of the Philippines Diliman.

Mohammed Yakub Razzaque. (2006). Alleged Number Two Leader of Rajah Sulayman Movement Still Evasive \& Remains the Last Irritant in the Almoest Obsolete Muslim Terrorist Group. Japanese Daily Newspaper Nihon Keizai Shimbun.

R. Hrair Dekmejian. (1995). Islam in Revolution Fundamentalism in the Arab World. New York: Syracuse University Press.

Rodolfo Mendoza. (2005). Philippine Jihad Inc. Unpublished Manuscript.

Rommel Banlaoi. (2006a). Radical Muslim terrorism in the Philippines. Dlm.)Andrew Tan. Handbook on Terrorism and Insurgency in Southeast Asia. London: Edward Elgar.

Rommel Banlaoi. (2006b). The Rise of Rajah Solaiman Movement (RSM): Suicide Terrorism in the Philippines. Singapore: Institute of Defence and Strategies Studies.

Tarra Quismundo \& Luige del Puerto. (2005). It's Death for Three Bombers. Philippine Daily Inquirer.

Yusuf Morales. (t.th). Radicalization in the Paradigm of the Filipino Muslims. Unpublished Research Monograph.

Yusuf al-Qaradhawi. (2012). Fatawa. Kuala Lumpur: Metro Book Distributor.

\section{Author's Biography}

Marlon Pontino Guleng@Muhammad Yusuf Marlon Abdullah, merupakan calon $\mathrm{PhD}$ serta lulusan sarjana dalam bidang Dakwah dan Kepimpinan daripada Universiti Kebangsaan Malaysia. Sebelum itu telah menamatkan pengajian di peringkat sarjana muda dalam bidang Dakwah \& Kepimpinan. Sekarang berkhidmat sebagai pensyarah di Kolej Universiti Islam Antarabangsa Selangor. Boleh dihubungi melalui email berikut: yusufmarlon@kuis.edu.my. 